\title{
Identification and characterization of ERp29 in rat spermatozoa during epididymal transit
}

\author{
Wei Guo, Fei Qu, Li Xia', Qiangsu Guo, Xiaoqian Ying and Zhide Ding \\ Shanghai Key Laboratory for Reproductive Medicine, Departments of Histology and Embryology and \\ ${ }^{1}$ Department of Patho-Physiology, School of Medicine, Shanghai Jiao Tong University, No. 280, Chong Qing Rd. \\ (South), Shanghai 200025, China
}

Correspondence should be addressed to Z Ding; Email: zding@shsmu.edu.cn

\begin{abstract}
The mammalian epididymis is able to create sequential changes in the composition of luminal fluid throughout its length, wherein spermatozoa undergo morphological, biochemical, and physiological modifications. Subsequently, spermatozoa acquire the ability for fertilization upon reaching the epididymal cauda. In this study, protein variations in Sprague-Dawley rat spermatozoa along the caput and caudal regions of epididymis were investigated by high-resolution two-dimensional gel electrophoresis (2DE) in combination with mass spectrometry. From total protein spots on the 2DE maps, 43 spots were shown to be significantly modified as sperm traverse the epididymis, and seven unambiguous proteins were identified from them. Finally, using indirect immunofluorescence, we demonstrated that localization of one of these seven proteins, the endoplasmic reticulum protein (ERp29) precursor, which was first reported in mammalian spermatozoa, was apparently up-regulated as the sperm underwent epididymal maturation and expressed mainly on caudal sperm. Western blot analysis also revealed that ERp29 precursor, from both whole spermatozoa and membrane proteins, increased significantly as the sperm underwent epididymal maturation. Furthermore, the results from immunofluorescence-stained epididymal frozen sections demonstrated that ERp29 was localized in cytoplasm of epididymal epithelia, and the fluorescence intensity was significantly higher in the caudal epididymis than in the caput. These clues indicated that the ERp29 precursor, perhaps related to secretory protein synthesis and absorbed by spermatozoa, may play a vital role in sperm maturation during the epididymal transit, particularly, in the sperm/organelle membrane.
\end{abstract}

Reproduction (2007) 133 575-584

\section{Introduction}

The epididymis is a long, convoluted, androgendependent tubule, through which spermatozoa leaving the testis must pass. Morphologically, the epididymis is divided into three segments: caput (proximal part), corpus, and cauda (Fig. 1; Jones 1998). While the caudal epididymis acts as a sperm reservoir, the caput and corpus are responsible for sperm maturation (Moore 1998, Gatti et al. 2004, Franca et al. 2005, McLean 2005). Mammalian spermatozoa undergo morphological, biochemical, and physiological modifications within the epididymis, which has a very active secretory and reabsorption function (Cooper 1998, Holland \& Nixon 1998, Dacheux et al. 2003, 2005, Toshimori 2003). Throughout its length, the epididymis is able to create sequential changes in the composition of luminal fluid, e.g. ions, solutes, proteins, and lipids (Kirchhoff et al. 1998, Nixon et al. 2002, Saez et al. 2003, Frenette et al. 2004, Gatti et al. 2005). The epithelial cells of the epididymis form a barrier to create a unique microenvironment in the lumen, where interactions between epithelial cells and spermatozoa take place via the fluid (Amann et al. 1993, Dacheux et al. 2003, 2005, Chan \& Zhang 2005, Sullivan et al. 2005). Thus, the interactions between sperm and the various molecules in the luminal fluid strongly indicate that these complex interactions are crucial for sperm maturation.

Recently, relevant topics dealing with spermatozoa maturation have focused on the events occurring in the internal components of spermatozoa, e.g. nucleus, acrosome, perinuclear theca, fibrous sheath, cytoplasmic droplet, and, especially, plasma membrane (Westhoff \& Kamp 1997, Cooper \& Yeung 2003, Mujica et al. 2003, Olson et al. 2003, 2004). However, results from different laboratories, using a variety of methods, are quite diverse in their findings on protein variations in the spermatozoa during epididymal transit (Dacheux et al. 2003, 2005, Saez et al. 2003, Toshimori 2003, Gatti et al. 2004). 


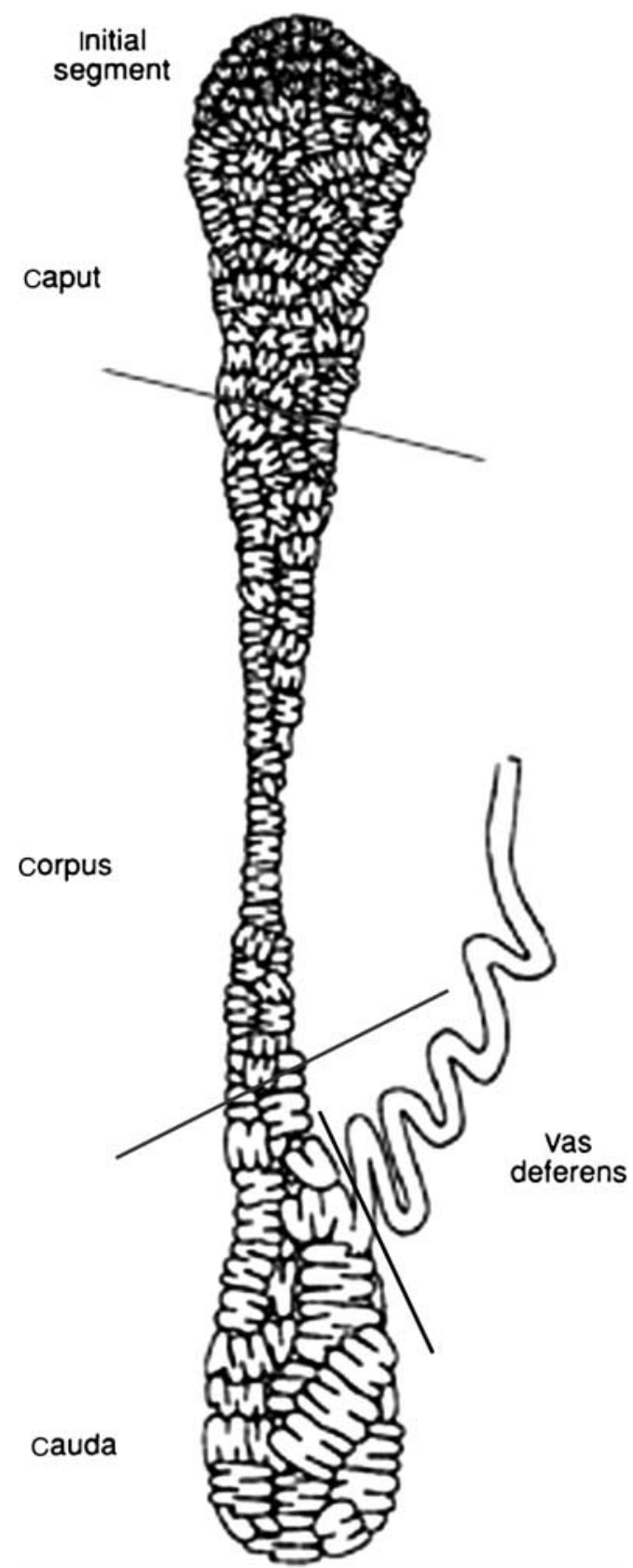

Figure 1 Schematic organization of the rat epididymis. Three regions of the epididymis - caput, corpus, and cauda - as well as the initial segment, are depicted. Dashed lines indicate sites where different regions were segmented.

In this study, we employed high-resolution twodimensional gel electrophoresis (2DE) and mass spectrometry to investigate protein variations in rat spermatozoa as they traverse the epididymis. We found that several proteins, including the ERp29 precursor, initially reported in mammalian spermatozoa, were modified/modulated significantly while undergoing epididymal maturation. These findings may provide crucial information for not only investigating the modification of sperm membrane, but also elucidating the mechanism of sperm maturation through the epididymis.

\section{Materials and Methods \\ Chemicals}

All reagents were the highest grade available (Bio-Rad), with the exception of low molecular weight standard, which was purchased from MBI Fermentas (Hanover, MD, USA) and Percoll, Triton X-100, HEPES, and phenyl methyl sulfonyl fluoride (PMSF) were obtained from Sigma-Aldrich (St Louis, Mo, USA).

\section{Animals and isolation of epididymal sperm}

Animal experiments were conducted according to the International Guiding Principles for Biomedical Research Involving Animal, as promulgated by the Society for the Study of Reproduction. Adult male Sprague-Dawley rats (aged 90-120 days) were purchased from the Shanghai Laboratory Animal Center (Jiu-Ting, Shanghai, China). Caput and caudal spermatozoa were extracted from every four rats for each experiment. Immediately, after the animals were killed, the epididymides were separated, and fat and overlying connective tissue carefully dissected out. Epididymal spermatozoa from caput and caudal segments were obtained following the method previously described by Acott and Hoskins (Acott \& Hoskins 1978). Spermatozoa were collected and centrifuged at $1000 \mathrm{~g}$ for $15 \mathrm{~min}$. To remove cytoplasmic droplets, extraneous materials, and cells, spermatozoa were centrifuged through a $10-50 \%$ discontinuous Percoll gradient. Finally, sperm concentration was assessed by hemocytometry. Contamination by somatic cells in each sperm preparation was $<0.1 \%$.

\section{Protein extraction and concentration}

Spermatozoa were homogenized in analysis buffer containing $1.5 \%$ Triton $\mathrm{X}-100$ and $1 \mathrm{mM}$ PMSF. The sperm suspension was then vortexed for $10 \mathrm{~min}$ at $4{ }^{\circ} \mathrm{C}$ and kept in a rotating ice bath for at least $2 \mathrm{~h}$ in order to allow proteins to dissolve completely. Ultrasonification $(50 \mathrm{~W}, 10 \mathrm{~s} \times 3$ times, VC600, Sonics and Materials, Inc., Newtown, CT, USA) and centrifugation $(12000 \mathrm{~g}, 10 \mathrm{~min})$ were then applied to get rid of the sediment. Membrane protein was isolated with the ReadyPrep Protein Extraction Kit (membrane I). For isoelectric focusing electrophoresis (IEF), the soluble fraction was desalted and concentrated through centrifugal filter units (Centricon Centrifugal Filter Unit with Ultracel YM-10 membrane; Millipore, Billerica, BA, USA), and then processed with the ReadyPrep 2D 
cleanup kit. The concentration of solubilized proteins was determined using the Reagent Compatible and Detergent Compatible protein assay kit.

\section{D gel electrophoresis and imaging analysis}

Aliquots of $200 \mu \mathrm{g}$ protein sample were diluted in $\sim 300 \mu \mathrm{l}$ rehydration buffer containing $8 \mathrm{M}$ urea, $2 \%$ $\mathrm{m} / \mathrm{v}$ CHAPS, $25 \mathrm{mM}$ dithiothreitol, $0.2 \%$ Bio-lyte (3-10 pl range), and $0.002 \%$ bromophenol blue. The sample was then applied onto a $17 \mathrm{~cm}$ immobilized $\mathrm{pH}$ gradient strip with a linear range of $\mathrm{pH} 3-10$, covered with mineral oil. First-dimension IEF was performed using a Protean IEF cell system at $17^{\circ} \mathrm{C}$ under the following conditions: $50 \mathrm{~V}$ for $12 \mathrm{~h}, 250 \mathrm{~V}$ for $30 \mathrm{~min}$, $500 \mathrm{~V}$ for $30 \mathrm{~min}, 1000 \mathrm{~V}$ for $1 \mathrm{~h}, 10000 \mathrm{~V}$ for $2 \mathrm{~h}$, and $10000 \mathrm{~V}$ for $50000 \mathrm{Vh}$ (Vhour). After equilibrating and alkylating, the electrophoresed strips were sealed onto the top of the second-dimension gels $(12 \%$ SDSpolyacrylamide gel) with $0.5 \%$ agarose. Silver staining using previously described modifications was followed (Rabilloud et al. 1992).

In this study, we repeated the 2DE experiment three times in order to confirm spot patterns before proceeding with further analysis. Replicates were scanned with a GS-800 calibrated densitometer using standardized parameters, and gel images were processed by PDQuest 7.2.0 software. Spot densities were determined after normalization, based on the total spot volumes on the gel. Protein spots, with significant changes in densities (paired $t$-test, $P<0.05$ ) in a consistent direction (increase or decrease), were considered to be different and selected for further identification.

\section{In-gel digestion and peptide extraction}

Selected protein spots were cut out from the 2DE gels using the Gelpix spot-excision robot (Genetix, Hampshire, UK), and washed three times with Milli-Q water. According to the manufacturer of ZipPlate micro-solid phase extraction (SPE) plate, gel pieces were transferred into ZipPlate micro-SPE plate wells (Millipore) and incubated in a silver de-staining solution (equal volumes of $30 \mathrm{mM}$ potassium ferricyanide and $100 \mathrm{mM}$ sodium thiosulfate) in a dark chamber for $20 \mathrm{~min}$ at room temperature. After being washed twice with Milli-Q water, gel pieces were washed twice in $25 \mathrm{mM}$ ammonium bicarbonate $/ 5 \%$ acetonitrile (ACN), $25 \mathrm{mM}$ ammonium bicarbonate $/ 50 \% \mathrm{ACN}$, and $100 \%$ ACN. When the gel pieces were dried, proteins were digested overnight with $10 \mu \mathrm{l}$ of trypsin $(10 \mathrm{ng} / \mu \mathrm{l}$, mass spectrometry grade, Promega) in $25 \mathrm{mM}$ ammonium bicarbonate at $37^{\circ} \mathrm{C}$. Peptide fragments, extracted with $0.2 \%$ trifluoroacetic acid (TFA) for $30 \mathrm{~min}$, were applied onto the $\mathrm{C} 18$ resin and then desalted with $0.2 \%$ TFA. Finally, the tryptic peptide mixtures were recovered by centrifugation at $1750 \mathrm{~g}$ for $15 \mathrm{~s}$ with $5 \mu$ l elution solution containing $50 \%$ ACN $/ 0.1 \%$ TFA.

\section{Mass spectrometry}

Tryptic peptides were lyophilized and suspended in $2 \mathrm{ml}$ of a matrix solution containing $10 \mathrm{mg} / \mathrm{ml} \alpha$-cyano-4hydroxycinnamic acid (CHCA) in 50\% ACN and $0.1 \%$ TFA. A $0.7 \mathrm{ml}$ aliquot was spotted onto the MALDI sample target plate. Peptide mass spectra were obtained from a MALDI-TOF/TOF mass spectrometer (4700 Proteomics Analyzer, Applied Biosystems, Foster City, CA, USA). Prior to real sample acquisition, six spots were calibrated for signal and parameter optimization. The peptide mass fingerprinting (PMF) was gained in the mass range of 800-4000 Da with $\sim 3000$ laser shots. To acquire spectra with mass accuracy of $<25 \mathrm{ppm}$, trypsin autolysis peaks were employed for internal calibration. Five of the most intense peaks, excluding those from the matrix, background, trypsin autolysis, acrylamide, or keratin peaks, were selected for subsequent MS/MS data acquisition. Then, the collision-induced energy was adjusted to 561027 Torr for MS/MS spectra acquisition.

Protein identification was processed and analyzed by Global Protein Server Workstation (Applied Biosystem), using MASCOT software of Matrix Science. Mass tolerance was limited to $50 \mathrm{ppm}$. Results from both the MS and MS/MS spectra were accepted as 'good identification' when the global protein server (GPS) score confidence was $>95 \%$.

\section{Western blotting}

SDS-PAGE was conducted on $25 \mu \mathrm{g}$ solubilized sperm protein using $12 \%$ polyacrylamide gels. Separated proteins were then transferred to PVDF membranes (GE Healthcare, Waukesha, WI, USA), using a semi-dry transfer apparatus (Bio-Rad). Membranes were blocked for $1 \mathrm{~h}$ at room temperature with Tris-buffered saline (TBS) containing $0.1 \%$ Tween-20 and 5\% BSA. Immunoblotting was performed with rabbit polyclonal ERp29 antibody (Abcam, Cambridge, MA, USA) at 1:1000 dilution overnight at $4{ }^{\circ} \mathrm{C}$. After washing with TBS, membranes were then incubated with a goat anti-rabbit secondary antibody conjugated to horseradish peroxidase (HRP, DakoCytomation, Glostrup, Denmark) at a 1:4000 dilution for $1 \mathrm{~h}$ at room temperature. Finally, signals were detected by ECL (ECL Plus, GE Healthcare Waukesha). In the meantime, $\beta$-actin served as the internal control.

\section{Immunofluorescent staining}

Tissue samples were obtained from rat epididymis, and snap frozen with Tissue-Tek optimal cutting temperature 
(OCT) compound (Fisher Scientific Co., Pittsburgh, Pennsylvania, USA). The segments of epididymal caput and cauda were cut into $6 \mu \mathrm{m}$ thick frozen sections. Caput and caudal spermatozoa were collected and smeared onto separate slides. Tissue sections and sperm slides were fixed in ice-cold acetone for $30 \mathrm{~min}$, and then blocked with $5 \%$ BSA in PBS for $30 \mathrm{~min}$ at room temperature, and later incubated either with rabbit antirat ERp29 antibody (1:500 dilution) in PBS overnight at $4{ }^{\circ} \mathrm{C}$ or with normal rabbit $\lg$ (1:500 dilution) as control. Samples were washed with PBS and incubated with a secondary antibody linked with fluorescein isothiocyanate (1:300 dilution; Rockland, Gilbertsville, $\mathrm{PA}$, USA) for $3 \mathrm{~h}$ at $37^{\circ} \mathrm{C}$. Digital photographs of fluorescent sections were viewed under a laser scanning confocal microscope (LSCM) and analyzed using the image analysis KS400 version 3.0 software packages (Carl Zeiss LSM-510; Carl Zeiss Vision, Munchen, Germany). The ratios of high fluorescence area (190255 gray level) in total fluorescence area (110-255 gray level) were calculated and compared. After taking photographs, the immunofluorescence-stained tissue sections were re-stained with hematoxylin/eosin (HE) and photos were taken again for cell discrimination.

\section{Results}

\section{Comparison of protein expression between the spermatozoa from caput and caudal epididymis}

To explore differences of protein expression between caput and caudal epididymal spermatozoa, the soluble sperm protein fraction was isolated by $2 \mathrm{DE}$. Three pairs of gels from different samples underwent the same treatment and were analyzed using PDQuest Image Analysis Software. A total of $807 \pm 63$ spots were detected on caput spermatozoa maps, while $844 \pm 57$ spots were detected on caudal. The overall protein expression profiles with pl range 3-10 and MW of $10-130 \mathrm{kDa}$ were very similar among the three samples from the different caput or caudal groups analyzed by PDQuest software, indicating higher stability and reproducibility of 2DE in our test system (Fig. 2). Spot densities were determined, with normalization based on total spot volumes on the gels. Protein spots, with significant changes in densities (paired $t$-test, $P<0.05$ ) in a consistent direction (increase or decrease), were judged to be deregulated, and were cut out for identification. Forty-three such deregulated spots were located, of which 24 were up-regulated and 19 down-regulated. An example is shown in Fig. 4A, where the spot was significantly up-regulated in caudal spermatozoa.

When variations of densities were more than three times, 16 spots were then successfully identified using MALDI-TOF/TOF mass spectrometry with PMF and/or MS/MS followed by database searching (Swiss-Prot protein database; Fig. 2, Table 1). We were able to identify seven unique proteins with high confidence (Fig. 3; Table 1). However, 16 spots representing seven unique proteins meant that some proteins were represented by at least two distinct spots on the 2DE gels. As summarized in Table 1, each of these seven proteins is characterized by its predicated $\mathrm{MW}, \mathrm{pl}$, mean fold, Swiss-Prot accession number, and regional abundance.
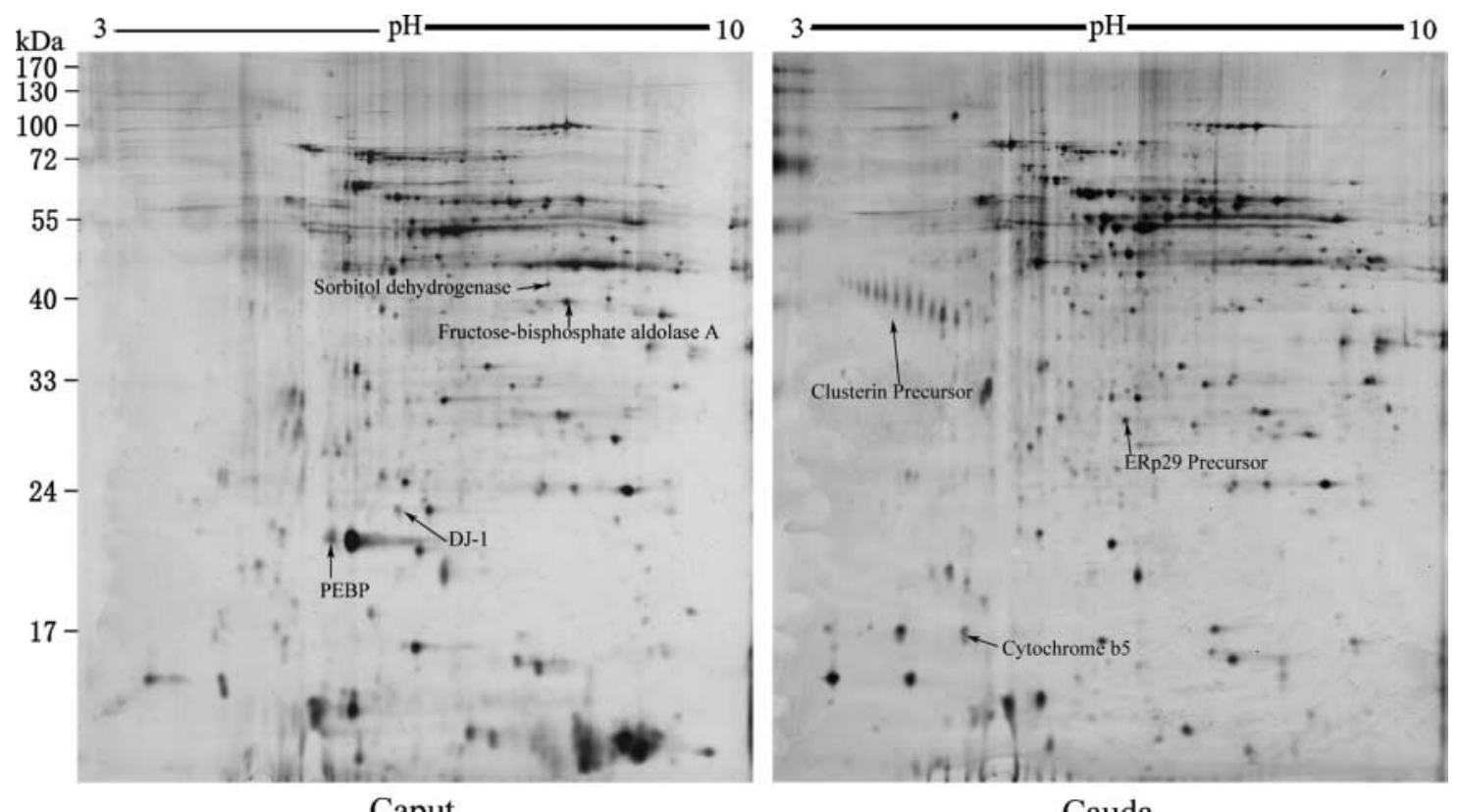

Caput

Cauda

Figure 2 Representative 2DE map of the protein extracts from rat caput and caudal epididymal spermatozoa. pl ranges ( $\mathrm{pH} 3-10)$ and MWs are indicated. Arrows identify spots in the gels (see also Table 1). 


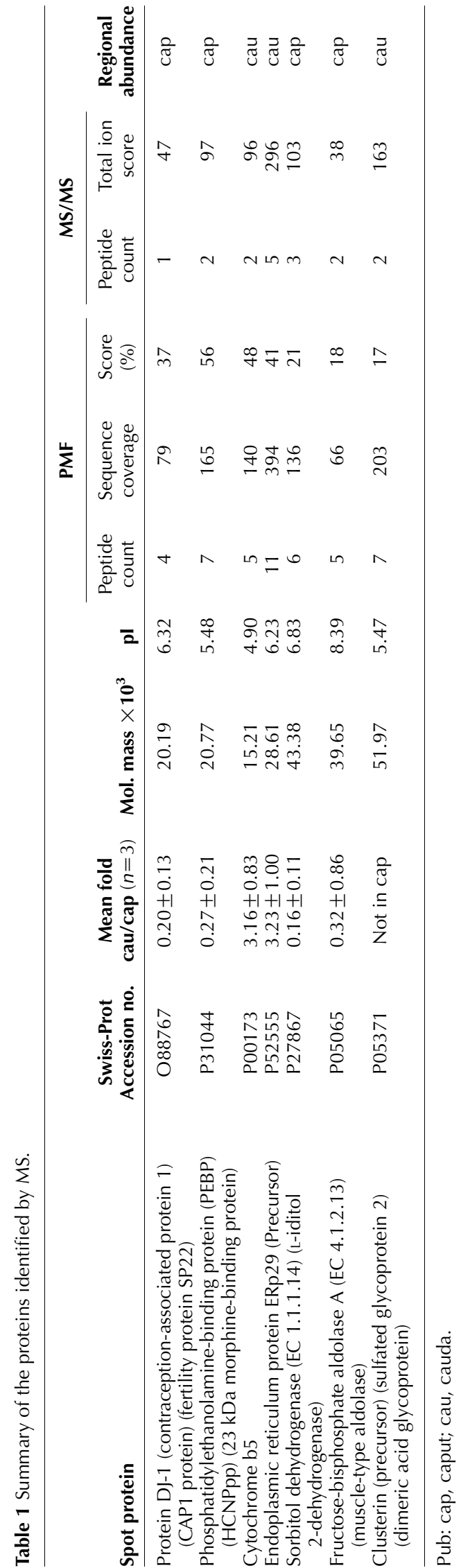

\section{Immunoblot analyses for ERp29 precursor}

Spot volume of the ERp29 precursor was enlarged in cauda compared with caput; the changing ratio reached $3.23 \pm 1.0 \quad$ (mean \pm s.D., $\quad n=3$ ), $P<0.01$ (Fig. 4A). In order to further confirm results of $2 \mathrm{DE}$, western blot analyses were performed using polyantibodies. Immunoreactions with the ERp29 precursor and $\beta$-actin antibodies were observed on PVDF membranes containing proteins from the caput and caudal sperm (Fig. 4B). The blotting intensity for the ERp29 precursor increased significantly on the PVDF membranes that contained proteins from the caudal sperm compared with those from the caput, with $\beta$-actin as an internal control. In western blotting of membrane proteins, the ERp29 precursor content was also higher in the caudal sperm than in the caput (Fig. 4C). These results verified that the ERp29 precursor is expressed mainly on caudal sperm.

\section{Localization of ERp29 precursor in epididymis and spermatozoa}

In order to further confirm the localization of the ERp29 precursor on epididymal spermatozoa, indirect immunofluorescent staining was performed using the anti-rat ERp29 antibody. Intense immunoreactivity was observed on the surfaces of whole caudal spermatozoa, including the sperm head (Fig. 5C). Caput spermatozoa, however, showed only a faint fluorescence on the anterior region of the tail (neck and middle piece, Fig. 5A). On the other hand, with the normal rabbit IgG as control, no evident reaction was detected on either the caput or caudal sperm (Fig. 5B and 5D). The immunofluorescencestained epididymal frozen sections, re-stained with $\mathrm{HE}$, demonstrated that ERp29 was localized in cytoplasm of epididymal epithelia (Fig. 6). In the same slide, the fluorescence intensity was significantly higher in the caudal epididymis than in the caput, measured and analyzed by LSCM and KS400. As the negative control, fluorescence was not detected in the sections incubated with normal rabbit IgG (figures not shown).

\section{Discussion}

In this study, high-resolution 2DE and mass spectrometry were employed to investigate protein variations in rat spermatozoa during epididymal transit. Seven proteins, whose expressions varied among the caput and caudal regions, were successfully identified with high confidence. Some proteins, such as clusterin, contraception-associated protein 1 (CAP1), and sorbitol dehydrogenase, have already been found to be related to rat spermatozoa and epididymis, but others were revealed for the first time, in particular, the ERp29 precursor. 
A ERp29 Precursor

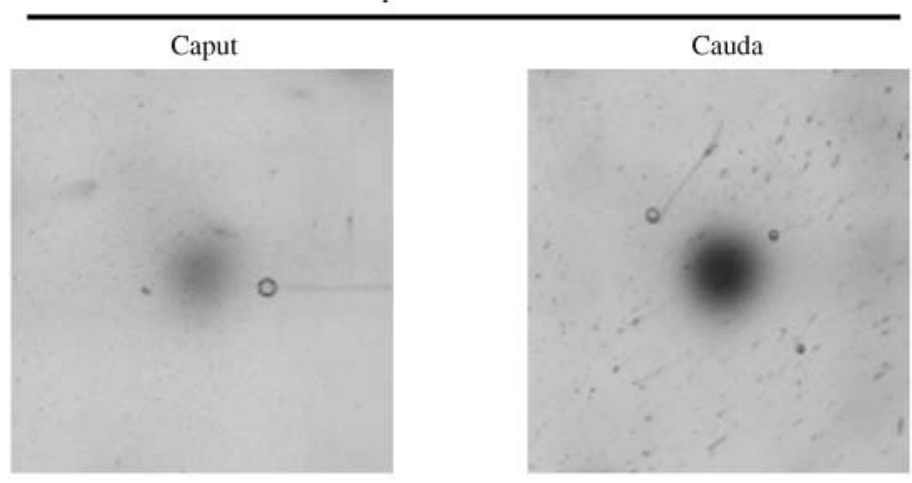

B

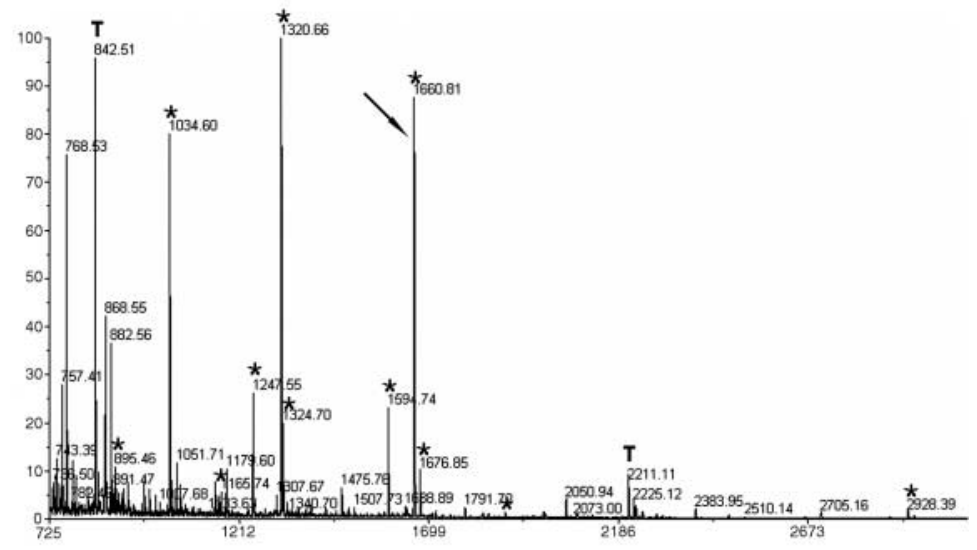

C

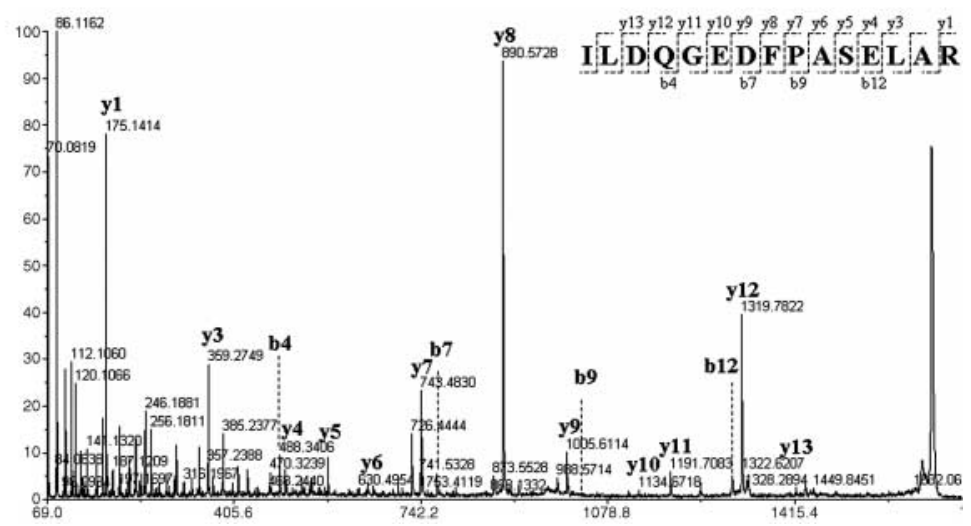

Figure 3 Representative protein spots identified with MS/MS. (A) The enlarged comparison between caput and caudal spots is identified as ERp29 precursor from the 2DE map. (B) Peptide mass fingerprinting of tryptic peptides revealing ERp29 in endoplasmic reticulum protein. ' $\mathrm{T}$ ' indicates trypsin autolytic peptides for internal calibration and asterisks indicate the peaks that matched this protein. The matched peptides occupy $41 \%$ sequence coverage and have a score of 394 . Arrow indicates ion at $m / z=1660.81$, selected for a MALDI-TOF/TOF tandem MS. (C) Fragmentation spectrum for ion $1660.81 \mathrm{y}$-ions, $\mathrm{b}$-ions in the spectrum. The $\mathrm{m} / \mathrm{z} 1660.81$ is one of the five abundant peaks selected for MS/MS acquisition. The identified sequence is ILDQGEDFPASELAR, interpreted as y series and $\mathrm{b}$ series ions that are indicated in the top right corner.

ERp29, a $29 \mathrm{kDa}$ protein, was first revealed during proteomic investigations of mammalian tissues (Demmer et al. 1997, Mkrtchian et al. 1998, Hubbard \& McHugh 2000). The ERp29 precursor has a signal peptide at the $\mathrm{N}$-terminus that is cleaved proteolytically upon entry into the endoplasmic reticulum (ER). Mature ERp29 (25.6 kDa, Mr=29000 on SDS-PAGE) has an
$\mathrm{N}$-terminal domain homologous to the thioredoxin-like domains in protein disulfide isomerase (PDI), and a C-terminal domain with similarities to the P5 subfamily of PDI (Hubbard et al. 2000, Liepinsh et al. 2001, Sargsyan et al. 2002a, 2002b, Mkrtchian \& Sandalova 2006); a KDEL-variant motif at the C-terminus specifies retention in the ER. ERp29 is expressed ubiquitously in 
Expression level

ERp29 Precursor

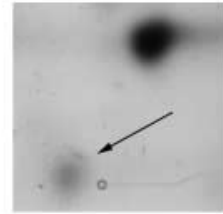

3D Viewer

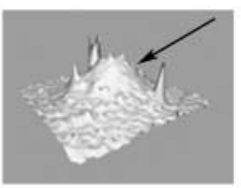

B

ERp29 Precursor (Total proteins)

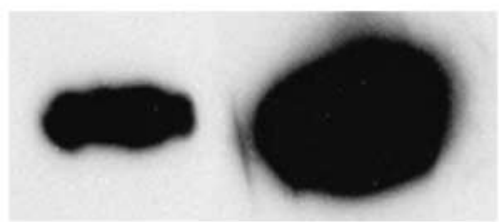

$\beta$-Actin

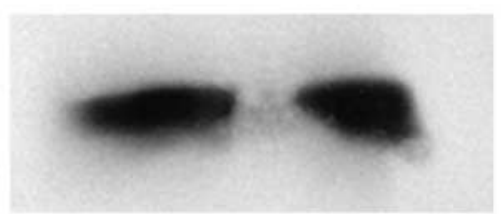

C

ERp29 Precursor

(Membrane proteins)

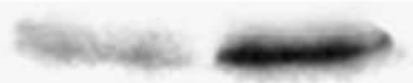

Figure 4 Representative altered protein spot in the 2DE map and its validation by western blot analysis. (A) The area indicating the spot (marked with arrow) was enlarged from the 2DE map. The spot, identified as the ERp29 precursor, was significantly up-regulated in the sperm from caudal epididymis. The trends of protein changes were expressed as upward folds of spot volumes $(3.23 \pm 1.0, n=3)$.

(B) Western blot analysis of ERp29 precursor shows the same changes as in the 2DE gels. (C) In membrane proteins, the ERp29 precursor content was also higher in the caudal sperm than in the caput. mammalian tissues, and homologous proteins have been identified in organisms as primitive as the fruit fly (Shnyder \& Hubbard 2002, MacLeod et al. 2004, Park et al.2005). These proteins are regarded to be specifically associated with the ER, mitochondria, Golgi, nuclei, or cell membrane (Huang et al. 2002). In humans, ERp29 is encoded by a single gene on chromosome 12 that has been highly conserved during mammalian evolution (Hubbard \& McHugh 2000, Mkrtchian \& Sandalova 2006). As ERp29 lacks the double cysteine motif, essential for PDI redox activity, it has been suggested that it plays a role in protein maturation and/or secretion, related to the chaperone function of PDI (Liepinsh et al. 2001, Mkrtchian \& Sandalova 2006), primarily in the production of endomembrane and secretory proteins (Shnyder \& Hubbard 2002, MacLeod et al. 2004). ERp29 is considered to be another major reticuloplasmin, thus adding distinct functionality to the ER machinery (Hubbard \& McHugh 2000, MacLeod et al. 2004, Hermann et al. 2005). All available data point to its important role in the formation of early secretory pathways within the ER (Mkrtchian et al. 1998, Hubbard et al. 2000, Liepinsh et al. 2001, Sargsyan et al. 2002a, 2002 b, Shnyder \& Hubbard 2002, MacLeod et al. 2004, Hermann et al. 2005, Park et al. 2005, Mkrtchian \& Sandalova 2006), possibly by participating in the folding of proteins. ERp29 assists in the protein folding as well as in the secretion of the secretory/plasma membrane proteins under the close cooperation with other ER chaperones and the ER stress signaler, PKR-like ER kinase (Park et al. 2005).

ERp29 also has distinctive regulatory and biochemical properties, including a distinct lack of calcium-binding activity (Demmer et al. 1997, Hubbard et al. 2000, Liepinsh et al. 2001, Shnyder \& Hubbard 2002, MacLeod et al. 2004, Hermann et al. 2005). Further evidence for ERp29's unique nature includes its novel tertiary structure (Liepinsh et al. 2001), lack of classical ER stress-response elements (Sargsyan et al. 2002a, 2002b), ability to bind
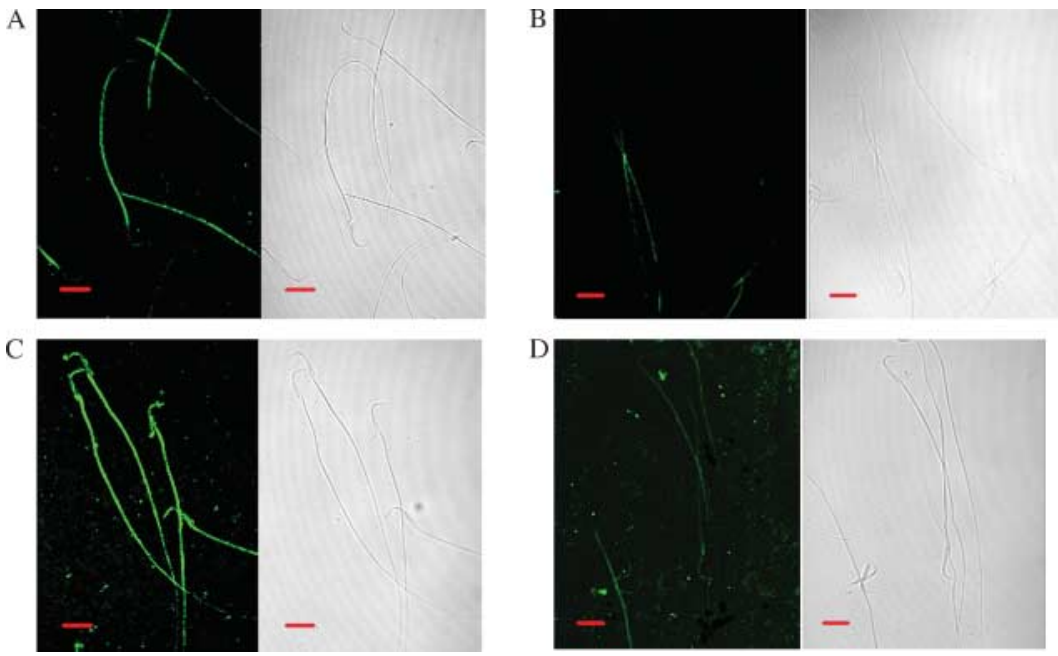

Figure 5 Localization of ERp29 precursor on the epididymal spermatozoa by indirect immunofluorescent staining, using LSCM. The right panel shows differential interference contrast (DIC) images corresponding to the left panel. (A) The localization of the ERp29 precursor on caput spermatozoa. (B) Caput spermatozoa incubated with normal rabbit $\operatorname{lgG}$ as control. (C) The localization of the ERp29 precursor on caudal spermatozoa. (D) Caudal spermatozoa incubated with normal rabbit IgG as control. Scale bar $=10 \mu \mathrm{m}$. 

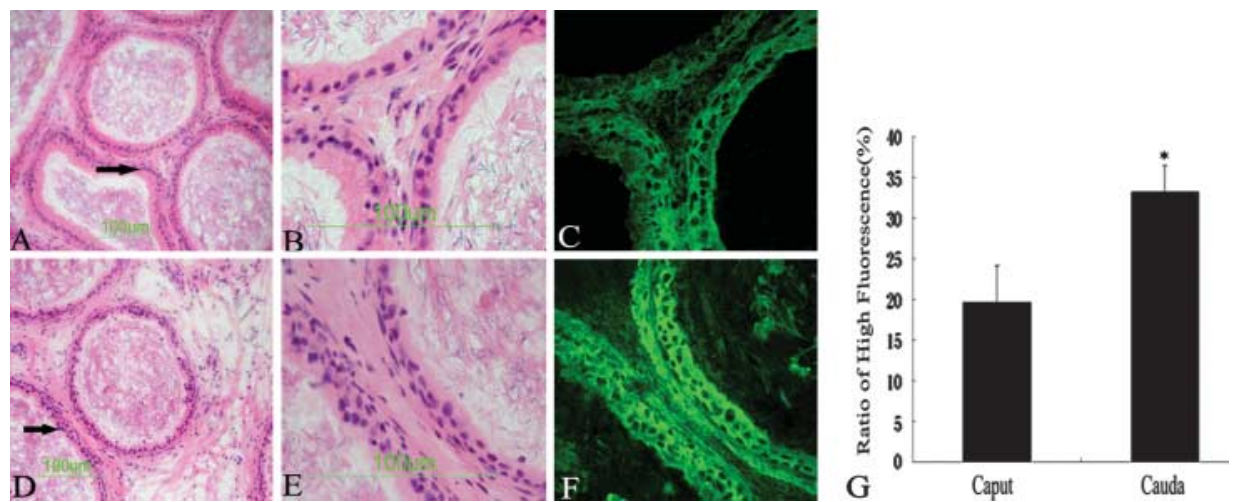

Figure 6 Immunofluorescent ERp29 precursor expression detection in rat caput or caudal epididymis in the same slide, followed by HE staining. (A) Caput epididymis was detected with HE staining. (B) A particular field within A (arrow) was magnified to show the detailed structure of caput epididymis. (C) The same field in B, detected with indirect immunofluorescence, shows that the ERp29 precursor was localized in cytoplasm of epididymal epithelia. (D) Caudal epididymis was shown by HE staining. (E) A field of interest shown in D (arrow) was magnified to show the detailed structure of caudal epididymis. (F) The same field in E, detected by indirect immunofluorescence, shows that the ERp29 precursor was expressed higher in the caudal epididymis. (G) The highest fluorescence ratio in 20 different sections was analyzed relative to the total fluorescent area obtained through KS400. Scale bar $=100 \mu \mathrm{m}$.

other ER proteins, and mediating membrane penetration or fusion (Magnuson et al. 2005). However, the functional characterization of ERp29, e.g. its specific molecular function, is far from completion and remains unknown.

In our 2DE map and mass spectrometry analyses, the ERp29 precursor was initially detected on rat spermatozoa. The quantity of the protein extracted from both spermatozoa and sperm membrane were dramatically increased during epididymal transit, as confirmed by western blot assay. Using indirect immunofluorescence, intense immunoreactivity was clearly observed on the whole tail of caudal spermatozoa, while only faint fluorescence was seen on the anterior region of the tail (neck and middle piece) of caput spermatozoa. In order to reveal the potential source of the protein on spermatozoa, immunofluorescence and HE staining for frozen sections demonstrated that ERp29 expression in rat epididymal epithelia was gradually increasing during the spermatozoa transit. ERp29 appears to be a secretory protein and might be absorbed by spermatozoa during epididymal transit. The PSORT II analysis program (http://www.psort. org/) predicted the four most probable localizations for ERp29 as being: extracellular (44.4\%), mitochondrial $(22.2 \%)$, ER $(22.2 \%)$, and vacuolar $(11.1 \%)$. These clues reveal that the ERp29 precursor might not only be an essential functional component of ER machinery, but also have its molecular function on the sperm membrane. ERp29 function may be comparable with that of calreticulin, which is another resident protein of the ER, present in the acrosome of both round spermatids and mature sperm, that is regarded to be an important factor in signal transduction in the reproductive system (Nakamura et al. 1993, Naaby-Hansen et al. 2001, Park et al. 2001, Ho \& Suarez 2003). Importantly, immunofluorescence and subcellular fractionation studies showed co-localization of ERp29 with calreticulin in the ER (Ferrari et al.
1998). On the other hand, caudal spermatozoa have an intact mitochondrial sheath, whose membrane maturation also needs the ERp29 involvement. Induction of caudal spermatozoa motility is likely dependent on a transient increase in cytosolic $\mathrm{Ca}^{2+}$ followed by a secondary increase in cyclic AMP. The rate of calcium transport into the sperm relies on the ability of mitochondrial $\mathrm{Ca}^{2+}$ uptake to maintain an adequate gradient for plasmalemma $\mathrm{Ca}^{2+}$ influx, whereas the rate of such transport is dependent in turn on the rate of aerobic respiration fueled by various substrates (Hoskins et al. 1978, Breitbart et al. 1990). Although ERp29 cannot bind calcium, it may have interactions with calciumbinding molecular chaperones on the membrane of mitochondrial sheath, e.g. calnexin or calreticulin, and indirectly influence calcium transport. Thus, ERp29 or its precursor could be presumed to be involved in the regulation of such cell functions such as sperm motility and acrosome reaction, as well as membrane maturation in sperm/organelle.

Mere identification of spermatozoa ERp29, however, is not sufficient to identify its entire biological function(s) in this event. Additional studies are still warranted to further clarify its roles. Undoubtedly, such endeavors may greatly help us to better understand and elucidate the mechanism(s) of the protein function and sperm maturation during epididymal transit.

\section{Acknowledgements}

The authors thank Mr Shixiao Qin, Ms Ruyao Wang, Ms Meige Lu, Ms Yanqin Hu, Ms Jinmei Wang (Shanghai Key Laboratory for Reproductive Medicine) and Mr Qingshen Hu (Department of Cell Biology) for their technical assistance. We feel grateful to Dr Jianli Shi (Department of Histology and Embryology) for 
her valuable advice. We thank Drs Kathryn Pokorny and Peter Reinach for their editorial assistance. This research project was supported by grants from the Shanghai Municipal Education Commission (No.03BK17), and the Shanghai Municipal Population and Family Planning Commission (No.2005JG07). The authors declare that there is no conflict of interest that would prejudice the impartiality of this scientific work.

\section{References}

Acott TS \& Hoskins DD 1978 Bovine sperm forward motility protein. Partial purification and characterization. Journal of Biological Chemistry 253 6744-6750.

Amann RP, Hammerstedt RH \& Veeramachaneni DN 1993 The epididymis and sperm maturation: a perspective. Reproduction, Fertility, and Development 5 361-381.

Breitbart H, Wehbie R \& Lardy H 1990 Regulation of calcium transport in bovine spermatozoa. Biochimica et Biophysica Acta 1027 72-78.

Chan HC \& Zhang YL 2005 Epididymial defensins and sperm maturation. Andrologia 37 200-201.

Cooper TG 1998 Interactions between epididymal secretions and spermatozoa. Journal of Reproduction and Fertility. Supplement $\mathbf{5 3}$ 119-136.

Cooper TG \& Yeung CH 2003 Acquisition of volume regulatory response of sperm upon maturation in the epididymis and the role of the cytoplasmic droplet. Microscopy Research and Technique 61 28-38.

Dacheux JL, Gatti JL \& Dacheux F 2003 Contribution of epididymal secretory proteins for spermatozoa maturation. Microscopy Research and Technique 61 7-17.

Dacheux JL, Castella S, Gatti JL \& Dacheux F 2005 Epididymal cell secretory activities and the role of proteins in boar sperm maturation. Theriogenology 63 319-341.

Demmer J, Zhou C \& Hubbard MJ 1997 Molecular cloning of ERp29, a novel and widely expressed resident of the endoplasmic reticulum. FEBS Letters 402 145-150.

Ferrari DM, Nguyen Van P, Kratzin HD \& Soling HD 1998 ERp28, a human endoplasmic-reticulum-lumenal protein, is a member of the protein disulfide isomerase family but lacks a CXXC thioredoxin-box motif. European Journal of Biochemistry 255 570-579.

Franca LR, Avelar GF \& Almeida FF 2005 Spermatogenesis and sperm transit through the epididymis in mammals with emphasis on pigs. Theriogenology 63 300-318.

Frenette G, Lessard C \& Sullivan R 2004 Polyol pathway along the bovine epididymis. Molecular Reproduction and Development 69 448-456.

Gatti JL, Castella S, Dacheux F, Ecroyd H, Metayer S, Thimon V \& Dacheux JL 2004 Post-testicular sperm environment and fertility. Animal Reproduction Science 82-83 321-339.

Gatti JL, Metayer S, Belghazi M, Dacheux F \& Dacheux JL 2005 Identification, proteomic profiling, and origin of ram epididymal fluid exosome-like vesicles. Biology of Reproduction 72 1452-1465.

Hermann VM, Cutfield JF \& Hubbard MJ 2005 Biophysical characterization of ERp29. Evidence for a key structural role of cysteine 125. Journal of Biological Chemistry 280 13529-13537.

Ho HC \& Suarez SS 2003 Characterization of the intracellular calcium store at the base of the sperm flagellum that regulates hyperactivated motility. Biology of Reproduction 68 1590-1596.

Holland MK \& Nixon B 1998 The specificity of epididymal secretory proteins. Journal of Reproduction and Fertility. Supplement $\mathbf{5 3}$ 197-210.

Hoskins DD, Brandt H \& Acott TS 1978 Initiation of sperm motility in the mammalian epididymis. Federation Proceedings 37 2534-2542.

Huang YH, Chang AY, Huang CM, Huang SW \& Chan SH 2002 Proteomic analysis of lipopolysaccharide-induced apoptosis in PC12 cells. Proteomics 2 1220-1228.
Hubbard MJ \& McHugh NJ 2000 Human ERp29: isolation, primary structural characterisation and two-dimensional gel mapping. Electrophoresis 21 3785-3796.

Hubbard MJ, McHugh NJ \& Carne DL 2000 Isolation of ERp29, a novel endoplasmic reticulum protein, from rat enamel cells evidence for a unique role in secretory-protein synthesis. European Journal of Biochemistry 267 1945-1957.

Jones RC 1998 Evolution of the vertebrate epididymis. Journal of Reproduction and Fertility. Supplement 53 163-181.

Kirchhoff C, Osterhoff C, Pera I \& Schroter S 1998 Function of human epididymal proteins in sperm maturation. Andrologia 30 225-232.

Liepinsh E, Baryshev M, Sharipo A, Ingelman-Sundberg M, Otting G \& Mkrtchian S 2001 Thioredoxin fold as homodimerization module in the putative chaperone ERp29: NMR structures of the domains and experimental model of the $51 \mathrm{kDa}$ dimer. Structure 9 457-471.

MacLeod JC, Sayer RJ, Lucocq JM \& Hubbard MJ 2004 ERp29, a general endoplasmic reticulum marker, is highly expressed throughout the brain. Journal of Comparative Neurology 477 29-42.

Magnuson B, Rainey EK, Benjamin T, Baryshev M, Mkrtchian S \& Tsai B 2005 ERp29 triggers a conformational change in polyomavirus to stimulate membrane binding. Molecular Cell 20 289-300.

McLean DJ 2005 Spermatogonial stem cell transplantation and testicular function. Cell and Tissue Research 322 21-31.

Mkrtchian S \& Sandalova T 2006 ERp29, an unusual redox-inactive member of the thioredoxin family. Antioxidants and Redox Signalling 8 325-337.

Mkrtchian S, Fang C, Hellman U \& Ingelman-Sundberg M 1998 A stress-inducible rat liver endoplasmic reticulum protein, ERp29. European Journal of Biochemistry 251 304-313.

Moore HD 1998 Contribution of epididymal factors to sperm maturation and storage. Andrologia 30 233-239.

Mujica A, Navarro-Garcia F, Hernandez-Gonzalez EO \& De Lourdes Juarez-Mosqueda M 2003 Perinuclear theca during spermatozoa maturation leading to fertilization. Microscopy Research and Technique 61 76-87.

Naaby-Hansen S, Wolkowicz MJ, Klotz K, Bush LA, Westbrook VA, Shibahara H, Shetty J, Coonrod SA, Reddi PP, Shannon J et al. 2001 Co-localization of the inositol 1,4,5-trisphosphate receptor and calreticulin in the equatorial segment and in membrane bounded vesicles in the cytoplasmic droplet of human spermatozoa. Molecular Human Reproduction 7 923-933.

Nakamura M, Moriya M, Baba T, Michikawa Y, Yamanobe T, Arai K, Okinaga S \& Kobayashi T 1993 An endoplasmic reticulum protein, calreticulin, is transported into the acrosome of rat sperm. Experimental Cell Research 205 101-110.

Nixon B, Jones RC, Hansen LA \& Holland MK 2002 Rabbit epididymal secretory proteins. I. Characterization and hormonal regulation. Biology of Reproduction 67 133-139.

Olson GE, Winfrey VP \& Nagdas SK 2003 Structural modification of the hamster sperm acrosome during posttesticular development in the epididymis. Microscopy Research and Technique 61 46-55.

Olson GE, Winfrey VP, Hill KE \& Burk RF RF 2004 Sequential development of flagellar defects in spermatids and epididymal spermatozoa of selenium-deficient rats. Reproduction 127 335-342.

Park BJ, Lee DG, Yu JR, Jung SK, Choi K, Lee J, Lee J, Kim YS, Lee JI, Kwon JY et al. 2001 Calreticulin, a calcium-binding molecular chaperone, is required for stress response and fertility in Caenorhabditis elegans. Molecular Biology of the Cell 12 2835-2845.

Park S, You KH, Shong M, Goo TW, Yun EY, Kang SW \& Kwon OY 2005 Overexpression of ERp29 in the thyrocytes of FRTL-5 cells. Molecular Biology Reports 32 7-13.

Rabilloud T, Brodard V, Peltre G, Righetti PG \& Ettori C 1992 Modified silver staining for immobilized $\mathrm{pH}$ gradients. Electrophoresis $\mathbf{1 3}$ 264-266.

Saez F, Frenette G \& Sullivan R 2003 Epididymosomes and prostasomes: their roles in posttesticular maturation of the sperm cells. Journal of Andrology 24 149-154. 
Sargsyan E, Baryshev M, Backlund M, Sharipo A \& Mkrtchian S 2002a Genomic organization and promoter characterization of the gene encoding a putative endoplasmic reticulum chaperone, ERp29. Gene 285 127-139.

Sargsyan E, Baryshev M, Szekely L, Sharipo A \& Mkrtchian S 2002b Identification of ERp29, an endoplasmic reticulum lumenal protein, as a new member of the thyroglobulin folding complex. Journal of Biological Chemistry 277 17009-17015.

Shnyder SD \& Hubbard MJ 2002 ERp29 is a ubiquitous resident of the endoplasmic reticulum with a distinct role in secretory protein production. Journal of Histochemistry and Cytochemistry 50 557-566.

Sullivan R, Saez F, Girouard J \& Frenette G 2005 Role of exosomes in sperm maturation during the transit along the male reproductive tract. Blood Cells, Molecules and Diseases 35 1-10.
Toshimori K 2003 Biology of spermatozoa maturation: an overview with an introduction to this issue. Microscopy Research and Technique 61 1-6.

Westhoff D \& Kamp G 1997 Glyceraldehyde 3-phosphate dehydrogenase is bound to the fibrous sheath of mammalian spermatozoa. Journal of Cell Science 110 1821-1829.

Received 17 August 2006

First decision 18 September 2006

Revised manuscript received 30 October 2006

Accepted 27 November 2006 